Pandemic H1N1 Targeted Messaging for Manitoba Metis: An Evaluation of a Risk Communication Intervention

\author{
S. Michelle Driedger, $\mathrm{PhD}$ \\ Associate Professor, Department of Community Health Sciences, University of \\ Manitoba \\ Ryan Maier, MA \\ Department of Community Health Sciences, University of Manitoba \\ Julianne Sanguins, $\mathrm{PhD}$ \\ Knowledge Development Manager, Health \& Wellness Department, Manitoba Metis \\ Federation, and Assistant Professor, Department of Community Health Sciences, \\ University of Manitoba \\ Sheila Carter \\ Director, Health \& Wellness Department, Manitoba Metis Federation \\ Judith G. Bartlett, M.D., CCFP, MSc \\ Department of Community Health Sciences, University of Manitoba
}

aboriginal policy studies Vol. 3, no. 1\&2, 2014, pp. 112-134

This article can be found at:

http://ejournals.library.ualberta.ca/index.php/aps/article/view/20022

ISSN: $1923-3299$

Article DOI: http://dx.doi.org/10.5663/aps.v3i1-2.20022

aboriginal policy studies is an online, peer-reviewed and multidisciplinary journal that publishes original, scholarly, and policy-relevant research on issues relevant to Métis, non-status Indians and urban Aboriginal people in Canada. For more information, please contact us at apsjournal@ualberta.ca or visit our website at www.ualberta.ca/nativestudies/aps/. 


\title{
Pandemic H1N1 Targeted Messaging for Manitoba Metis: An Evaluation of a Risk Communication Intervention
}

\author{
S. Michelle Driedger, PhD \\ Associate Professor, Department of Community Health Sciences, University of Manitoba \\ Ryan Maier, MA \\ Department of Community Health Sciences, University of Manitoba
}

Julianne Sanguins, $\mathrm{PhD}$

Knowledge Development Manager, Health \& Wellness Department, Manitoba Metis Federation, and Assistant Professor, Department of Community Health Sciences, University of Manitoba

Sheila Carter

Director, Health \& Wellness Department, Manitoba Metis Federation

Judith G. Bartlett, M.D., CCFP, MSc

Department of Community Health Sciences, University of Manitoba

\begin{abstract}
Certain populations are more at-risk than others during a pandemic, and health systems are required to develop targeted risk messaging to ensure that those populations have access to necessary protective materials and information. During the H1N1 pandemic in 2009-2010, the Manitoba Metis Federation (MMF), with support from Manitoba Health, carried out a door-to-door risk communication campaign that targeted particularly at-risk Metis in Manitoba, Canada. This paper is an evaluation of that campaign. To investigate Metis perceptions of the intervention, researchers conducted five focus groups ( $n=50$ participants) with Metis citizens in two communities where targeted home visitations were carried out. To understand the rationale and intentions of the intervention, researchers also carried out key informant interviews with MMF senior staff who were responsible for developing the intervention and delivering the training to the communication messengers. Despite the positive steps taken to reach an at-risk community, the outcomes of this particular intervention ultimately did not meet its intended goals. Efforts can be made during inter-pandemic periods to build on established relationships, learn from past experiences, and develop new solutions. To ensure optimum community reception, intensive health messaging campaigns need to strategize ways to impart health expertise in ways that are culturally relevant.
\end{abstract}

\section{Introduction}

The World Health Organization classified the H1N1 influenza as a pandemic on 11 June 2009 (World Health Organization 2009). At all jurisdictional levels, health systems

aboriginal policy studies, vol. 3, no. 1\&2, 2014

www.ualberta.ca/nativestudies/aps/

ISSN: $1923-3299$ 
in Canada implemented pandemic response plans and made considerable investments in efforts to mitigate the severity and the spread of the pandemic. The first weeks and months of the pandemic were characterized by considerable uncertainty; however, it soon became apparent that the virus was affecting certain populations much more than others. In particular, the rates of H1N1 infection were disproportionately high for Aboriginal populations in Canada and for Indigenous peoples around the world (La Ruche et al. 2009; Massey et al. 2011; Boggild et al. 2011).

During the pandemic, the Manitoba Metis ${ }^{1}$ Federation, with support from the province of Manitoba's Health Department (Manitoba Health), carried out a door-todoor informational messaging campaign to Metis households in remote, isolated, and rural areas of Manitoba. The intervention was designed to ensure that a potentially at-risk population had the necessary information to better protect themselves and their families from the H1N1 virus. The research presented in this article is an evaluation of how Metis individuals living in areas targeted by the intervention perceived the messaging campaign, as gathered via key informant interviews and focus groups. This evaluation was conducted at the request of the Manitoba Metis Federation, and was added to a broader research study examining issues related to risk and trust and how Metis in Manitoba perceive public health issues and their management by health decision-makers (Driedger et al. 2009-2010; Driedger et al 2010-2013).

\section{Background}

\section{The Metis People, Where They Live, and Their Health Services}

Metis are constitutionally defined as one of Canada's Aboriginal peoples and are a nation of blended First Nations and European heritages (Government of Canada 1982). While an ethnogenesis can be traced back to the seventeenth and eighteenth centuries, the coalescence of a distinct Metis cultural and political self-consciousness developed in the early nineteenth century around the junction of the Red and Assiniboine Rivers in contemporary Manitoba (Andersen 2008). Manitoba currently has one of the highest Metis populations in Canada, with approximately 71,805 people who self-identify as Metis (Statistics Canada 2008). Like other Aboriginal peoples in Canada, Metis have similar, yet unique, histories of colonialism and marginalization that are underpinned by a persistent and pervasive public and institutionalized racism (Adelson 2005). Most notably, after the Red River Resistance in 1869-70 and the fall of Batoche in 1885, "Metis were denied a

1 The Manitoba Metis Federation uses the unaccented "e" in Metis to signify the status of Manitoba as the birthplace of the Metis Nation (Manitoba Metis Federation 2013a). This usage shall also be adopted in this paper.

2 While the Red River Resistance facilitated the entrance of Manitoba into Canadian Confederation on terms that seemed favorable to the Metis, the federal government failed to fulfill its obligations to ensure a land base for the Metis, allowing land speculators and an influx of new settlers to eventually take over most of the land. The Battle of Batoche in 1885-the culmination of the "North-West Resistance," and again in response to the looming dispossession of an Aboriginal land-base as part of the Canadian nation-building project-marked the final defeat for the Metis in attempting to secure a distinct geo-political place for the Metis as a nation. 
separate identity and ignored for a century" (McMillan 1995, 312). These histories have had a direct influence on where Metis live today as well as on their health status, access to health services, and quality of service available (Martens 2010, Bartlett, et al. 2010; Dickason 1992; Gaudry 2013; Tang and Browne 2008).

The political and military defeats noted above led to a generalized Metis diaspora (Andersen 2008). Many families dispersed across the Prairies and were forced to try to assimilate into dominant populations, while many others settled alongside First Nations reserves or on Crown lands called "road allowances" (McMillan 1995). In Manitoba, Metis came to live diffusely in the province's cities, towns, villages, and unorganized territories. In many places they were nevertheless followed by the discriminatory attitudes and actions of the general public, as well as of social and political institutions, which contributed to continued marginalization and social exclusion (McMillan 1995). Currently, Metis who live in northern communities in Manitoba generally fall under a municipal governance structure that is overseen by the provincial department of Aboriginal and Northern Affairs (ANA). ANA provides the infrastructure and municipal services to approximately fifty northern communities and also supports each community's Northern Affairs Community Council (NACC) and a Council office within the community. Many ANA communities that are adjacent to remote or isolated First Nations reserves do not have modern water and sewer infrastructure, and face challenges of inadequate housing and access to basic services, including health services (Government of Manitoba n.d. a).

While the federal government provides and operates health services for First Nations and Inuit, Metis fall under provincial jurisdiction for health services, and access the health care system in the same way as the general population (Haworth-Brockman, Bent, and Havelock 2009). ${ }^{3}$ In northern areas of Manitoba, however, access to health care is more challenging. Rural residents are often significant distances from their nearest provincially run primary healthcare centres. Many remote and isolated ANA communities may only have a small community health centre, which is usually staffed by a single community health worker, along with occasional itinerant physician services (Government of Manitoba n.d. b). Some ANA communities adjacent to First Nations reserves ostensibly access care from federally run nursing stations on-reserve-an arrangement agreed to by the federal and provincial health departments in 1964 (Cook 2003). However, these nursing stations may not be sufficiently supplied and staffed to respond to a surge of patients seeking care from outside the community.

\section{The Manitoba Metis Federation}

The Manitoba Metis Federation (MMF) was founded in 1967 as a self-governing official representative organization of the Metis Nation in Manitoba. Organized into seven Regions and approximately 140 Locals across the province, the MMF advocates

3 How this jurisdictional constellation will persist into the future remains to be seen, as a new federal court ruling in 2013 has now deemed the Metis to be defined as "Indian" and thus within federal jurisdiction (Federal Court of Canada 2013). 
for the political, economic, cultural rights, and social interests of the Manitoba Metis. In addition to providing a variety of programs and services, the MMF engages with provincial and federal governments to access funds and influence policies that affect Metis people (Manitoba Metis Federation 2013b). The MMF is headquartered in the provincial capital of Winnipeg, which is home to most of the MMF departments that sustain a province-wide focus. Satellite staff for a number of departments are based in the MMF's regional offices where the scope of activities is more localized (Martens 2010, Bartlett, et al. 2010). The two departments relevant to this evaluation are the Health \& Wellness Department (MMFHWD) and the Metis Community Liaison Department (MMF-MCLD).

While the MMF-HWD does not provide health services to Metis, one of its key functions is to fill a long-standing gap in Metis-specific health research (Furgal, Garvin, and Jardine 2010; Kumar, Wesche, and McGuire 2012). Notably, in 2010 the MMF-HWDin partnership with the University of Manitoba-published a population-based study (The Metis Atlas) on the health status of Metis in Manitoba. In one of its key roles, the MMF-HWD engages with provincial and regional health systems via regional knowledge networks to translate knowledge and adapt policy and programming to better meet Metis health needs (Martens 2010, Bartlett, et al. 2010; Bartlett, Carter, Sanguins, and Garner 2012; Sanguins et al. 2012). This engagement mechanism was already well established when the pandemic struck in 2009.

The MMF-MCLD, on the other hand, has a more defined role as service providers to Metis citizens, offering supports and advocacy services for Metis families. Initially created to assist Metis with finding foster care and adoption services, it has since expanded its mandate to include client and family support, referral and advocacy, reunification, elder support, and repatriation. MMF-MCLD roles entail considerable direct involvement with the Metis population throughout Manitoba (Manitoba Metis Federation 2013c).

\section{Pandemic Vulnerability}

Aboriginal populations have been hit disproportionately hard by past pandemics (Rudge and Massey 2010) and they likewise suffered a significant burden during the H1N1 pandemic in Canada (Boggild et al. 2011). These higher rates of infection mirror existing health disparities and are similarly rooted in complex, often underlying, and inter-related social determinants of health that influence susceptibility and levels of exposure, severity, and course of recovery during a pandemic (Quinn 2008; Blumenshine et al. 2008; Spence and White 2010). Distally rooted in the colonial experience, many determinants are based on historic and contemporary economic and political structures that individuals have had little to no control over (Adelson 2005; Reading and Wien 2009). For example, First Nations reserves in northern Manitoba were hit exceptionally hard during the first wave and this has been attributed to a variety of co-mingling factors: access to clean water, housing conditions and overcrowding, and community isolation (Pollock et al. 2012). A point that needs to be stressed here is that this vulnerability is not indicative of an inherent inability of Aboriginal peoples to take care of themselves and their health, but reflects a history 
of sustained, structural prejudice and racism realized in policy, or the absence of policy, that has cumulatively resulted in poorer health outcomes which thereby placed people at greater risk (Baker and Giles 2012). Evolving as it did within the context of a colonial state, the healthcare system itself has been shown to be characterized by an institutionalized racism (Tang and Browne 2008; Browne et al. 2010; Browne 2007; Lux 2001, 2010), indeed sharing this trait with other Canadian political and legal institutions (Thobani 2007). Institutionalized racism, overlapped with chronic interpersonal experiences of racism, has been shown to contribute to poorer health outcomes (Larson et al. 2007). Therefore, the prospect of seeking out and accessing treatment involves particular barriers for Aboriginal people, and adds another complicating factor to the issue of pandemic vulnerability.

Those living in northern ANA communities face many of the same daily challenges as do northern First Nation reserves, and it is not surprising that Metis living in more northern areas of Manitoba have poorer health status. Metis have higher rates of chronic disease, including ischemic heart disease, diabetes, and a higher prevalence of total respiratory morbidity (Martens 2010, Bartlett, et al. 2010). Metis also have higher rates of smoking and teen pregnancy (Martens 2010, Bartlett, et al. 2010), and have a lower median age than the general population (Statistics Canada 2008). While Metis-specific data for H1N1 infection are not available, all of the above have been linked to increased infection and mortality rates with H1N1 influenza (Hewagama et al. 2010; Louie et al. 2009; Pebody et al. 2010; Spence and White 2010), and further indicate that the Metis were a particularly vulnerable population during the pandemic.

\section{Risk Communication and Vulnerable Populations}

Risk communication is challenging during pandemics because of their uncertain and dynamic nature. Messaging needs to be clear, consistent, and employ a variety of mediums: print, radio, television, and internet (Jehn et al. 2011; Freiman et al. 2011). Timing is crucial, with potential pitfalls ranging from message fatigue and declining risk perception if initiated too early and intensely, to being too late to be effective (Gray et al. 2012). Reaching vulnerable populations adds further complexity, and demands targeted and tailored messaging to avoid "one-size-fits-all" approaches that ignore particular realities and challenges that communities can face (Gray et al. 2012; Hutchins et al. 2009).

Effective messaging to historically marginalized communities requires credible communication that builds trust, instructs, and informs (Vaughan and Tinker 2009; Giles, Castleden, and Baker 2010). Critical, however, is involving communities in respectful partnerships for pandemic planning. Collaborating with communities can mitigate historical power imbalances (Gray et al.2012), add greater legitimacy to the communications (Lee, Rogers, and Braunack-Mayer 2008), supply health systems with culturally appropriate community knowledge, and identify potential challenges and barriers in reaching the community (Uscher-Pines et al. 2007). Effective community-based dissemination requires: in-community networks; local "go-to" people who are accessible, trusted, well-informed, and trained to give advice; or local Aboriginal health workers (Rudge and Massey 2010; 
Massey et al. 2011; Massey et al. 2009). Given that marginalized communities will tend to experience disproportionate rates of infection, effective communication becomes a matter of social justice (Lee, Rogers, and Braunack-Mayer 2008).

One way to reach a targeted audience is through in-home, in-person visits. Traditionally focussed on childhood development, home health visitations evolved out of a recognition that many diseases were preventable and often the result of living conditions. These efforts have usually targeted vulnerable families, and generally included education on hygiene, sanitation, and promoting general family health (Byrd 1995; Government of Manitoba 2010a). The most successful home visiting strategies are long-term interventions that allow relationships to build between families and the health visitor, and are most effectively carried out by nursing professionals rather than lay community members (Kearney, York, and Deatrick 2000; Government of Manitoba 2010a). Although home health visits have often followed an antecedent event, there is currently no relevant literature on home visiting strategies being used to convey targeted risk communications to a discrete population during a pandemic. Furthermore, the evaluation of pandemic, or event-specific, risk communication is still a developing field of inquiry (Glik 2007), and evaluating any risk communication campaign is vital to identify what worked and what did not (Jardine 2008; U.S. National Research Council 1989).

\section{Health Systems Respond to H1N1}

Upon the declaration of the pandemic in Canada, the Manitoba government established a collaborative mechanism through which stakeholders could regularly meet to address the pandemic and its impact on Aboriginal populations. The H1N1 Tripartite Table included representatives from both provincial and federal health agencies, and representatives from Aboriginal self-governments-in this case, the Manitoba Metis Federation, and First Nations organizations. The Tripartite Table allowed stakeholders to meet frequently, identify problems, exchange information, and generate solutions (Government of Manitoba 2010b).

A key responsibility of the province was to keep Manitobans informed about the pandemic, and communication campaigns directed at the general population took on a variety of forms, including an informational $\mathrm{H} 1 \mathrm{~N} 1$ guide distributed to all households in the province in the fall of 2009 . H1N1 risk messaging to residents included flu prevention behaviors similar to those found in seasonal flu campaigns (wash hands frequently, cover your coughs, and stay home when ill). People were also urged to assemble a household flu kit that included a thermometer, soap, and fever-reducing medications (Government of Manitoba 2009).

\section{Interventions to Protect Metis From H1N1}

To mitigate the potential severity of the second wave of the pandemic, the MMF and Manitoba Health agreed to three related interventions. Recognizing that ANA communities face considerable challenges accessing clean water, health services, and acquiring protective 
and treatment supplies, approximately 2,500 flu kits were delivered to ANA communities. Kits contained hand sanitizer, adult and infant acetaminophen, Children’s Motrin ${ }^{\circledR}$, a digital thermometer, and basic information on prevention and self-care (Government of Manitoba 2010b). Secondly, the MMF and Manitoba Health collaborated on a targeted informational mail-out that was sent to the entire MMF registry. The mail-out included information on self-care and caring for a child with a fever, plus posters on hand-washing and cough etiquette both in English and in the Metis language, Michif. The mail-out also contained a plain language letter signed by the MMF president and Manitoba's minister of health, indicating that both were working closely together to ensure that Metis had the information they needed to protect themselves from the pandemic (Manitoba Metis Federation, key informant interview, 7 July 2011). Lastly, the province funded a door-to-door messaging campaign carried out by MMF-MCLD staff. This intervention targeted Metis living in more rural, remote, and isolated areas of the province where Metis populations had lower health status, as identified by the Metis Atlas (Martens 2010, Bartlett, et al. 2010). In other words, home visitations targeted those Metis who could potentially be the most vulnerable to the pandemic, most of whom live in northern ANA communities. The MMF-HWD drafted a proposal for the intervention near the beginning of the second wave of the pandemic, and following the approval and agreement for funding by the province, the intervention was completed in early 2010. A pandemic is a novel context for the use of home health visitations, and this article will evaluate the effectiveness of this campaign to provide pandemic risk communications to Metis in Manitoba.

\section{Methods}

Data were collected using key informant interviews with representatives who had intimate knowledge about how the Manitoba Health and MMF interventions were developed, as well as through focus groups with Metis. Standard interview protocols (Krueger 1988; Liamputtong 2011; Morgan and Krueger 1993; Crabtree and Miller 1999; Gilchrist 1992; Patton 2002) were followed: audio recording of interviews, verbatim transcripts of audio-files, audio-verifying written transcripts against the audio-file for accuracy, researcher field notes taken following the interviews, and collaborative discussions among members of the research team throughout the process. Research ethics approval was obtained by the University of Manitoba Health Research Ethics Board (Reference number: H2010:008). Via a research partnership with the MMF, and in keeping with community-based research approaches (Israel et al. 1998), the Metis community collaborated and participated in all phases of the research project, from requesting the evaluation of the intervention, ensuring that community cultural protocols were followed, and working with the University of Manitoba researchers to interpret and disseminate the results. Recruitment for the focus groups was facilitated through the partnership with the MMF-MCLD, who placed posters in strategic locations within the community as well as through word of mouth in the community. In-community assistance with recruitment not only ensured that all focus groups in the small communities were sufficiently attended, but 
also that attendees felt comfortable in sharing their experiences. Additionally, the focus groups were all led by a well-experienced facilitator-either the principle investigator or senior research associate - to ensure that all participants had opportunities to share in the discussion. The principle investigator is Metis, and the research associate holds an MA in Native Studies and has had extensive experience conducting focus groups and interviews with indigenous communities. All focus group participants were paid an honorarium of $\$ 50$ for their time and expenses. While focus groups were conducted in both urban and rural/remote settings, only the rural/remote focus group conversations form the basis of this evaluation, as they were the only ones to receive the home visitation component of the pandemic intervention. Researchers visited two communities in mid- to northern Manitoba MMF Regions where MMF-MCLD staff had conducted home health visitations. In total, Metis citizens participated in five focus groups between the two communities, with a total of fifty participants. Table 1 shows the breakdown of participants by age and gender. Focus groups were conducted in late 2010 shortly after the World Health Organization declared that the virus had entered a post-pandemic phase (10 August 2010) (World Health Organization 2010). Researchers conducted key informant interviews with MMF staff in the summer of 2011 to record the rationale and instructions given to MCLD staff for carrying out the messaging campaign.

TABLE 1: Demographic information for Metis focus group participants

\begin{tabular}{|l|l|l|l|l|l|}
\hline Date & Location & Age Group & Total Participants & Men & Women \\
\hline Oct. 18, 2010 & Region 1 & $18-34$ & 9 & 3 & 6 \\
\hline Oct. 18, 2010 & Region 1 & $35-54$ & 11 & 5 & 6 \\
\hline Oct. 19, 2010 & Region 1 & $55+$ & 11 & 3 & 8 \\
\hline Nov. 4, 2010 & Region 2 & $35-54$ & 7 & 2 & 5 \\
\hline Nov. 4, 2010 & Region 2 & $18-65$ & 12 & 5 & 7 \\
\hline
\end{tabular}

A fundamental component of the focus groups was sharing in a fellowship of food through a communal meal. For the rural/remote focus groups, this meal was prepared by a local community member who was reimbursed for their time, their supplies, and their culinary creations.

Transcribed data and researcher field notes were imported into $\mathrm{NVivo}^{\mathrm{Tm}}$ for analysis. NVivo $9^{\text {rx }}$ helps to facilitate data management and retrieval, but all the analysis is researcherdriven. Several transcripts were read iteratively by the project lead and senior research associate to develop a coding guide to capture emergent ideas and concepts relevant to the Metis participants. Once the coding guide was developed, two research assistants were trained on its use to be applied across all the focus group data. Inter-rater reliability scores were 94 percent, showing a high level of consistency. Also, the coders often worked within the same space and were able to resolve any conflicts through open discussion. Constant 
comparison between thematic ideas and concepts in the literature as well as across focus groups was used throughout the process to ensure that analysis was not being closed prematurely. Individual key informant interviews were coded in a similar manner. Once the entire dataset was coded at a descriptive or surface level, broader discussions of the data and critical reading of different concept categories were carried out within the team.

Interpretations of the focus group data was shared back with Metis participants in a number of ways. A descriptive report was shared by mail to Metis who requested to know what other Metis had to say in the other focus groups. In addition, we attended the 2011 Manitoba Metis Federation Annual General Assembly. At this event, we had a booth set up to share more broadly with Manitoba Metis what our project had learned from the Metis who participated. We developed a pamphlet with a high-level plain language summary of the project findings. As many Metis asked the research team questions during the focus groups about pandemic H1N1 and influenza, we developed a list of "frequently asked questions," with plain language responses that had been vetted by a medical doctor to ensure accuracy. Additionally, to engage Metis children, we developed a colouring sheet that illustrated different strategies Metis participants discussed doing during pandemic H1N1 (e.g., hand washing) and an activity page (e.g., word search puzzle) about key protective health messaging for any cold and flu season. The colouring page was especially effective at engaging some Metis elders who did not want to take written materials but who told stories about their experiences while pointing to different illustrations. We also spent a great deal of time just talking to Metis who stopped at our booth. Materials were subsequently taken back to the different regions of the MMF through the MMF-MCLD staff to put in the ANA offices for Metis who were unable to attend the Annual General Assembly. Further, the evaluation of the MMF-Manitoba Health intervention was first shared with the MMF-HWD office to ensure accuracy of facts and context so that they could assist in the interpretation of results (Maier, Cooper, and Driedger 2012).

\section{Results}

\section{Intervention Rationale}

The Tripartite Table allowed the Metis community to provide Metis-specific health knowledge to provincial health authorities. Using preliminary data from the soon-tobe-released Metis Atlas, the MMF could shed light on the poorer health status of Metis living in the more northern areas of the province and so show the extent of potential Metis vulnerability to the pandemic:

They're starting to at least understand that there's another population out there with really terrible health status that's at risk for this and live under similar conditions [as many reserve communities] (Manitoba Metis Federation, key informant interview, 7 July 2011). 
In an attempt to offset this vulnerability, the MMF and the province wanted to be sure that Metis living in rural, remote, and isolated areas had the necessary information on self-care and prevention. They also wanted residents to know that kits were available to them at ANA offices. The goal was to reinforce this information by the most direct means possible: going door-to-door.

In the education piece of going door to door, first to find out did you get a kit; if not, tell them where they could get it and give them information about cough etiquette, stuff like that (Manitoba Metis Federation, key informant interview, 7 July 2011).

Metis residents living in remote areas may feel particularly isolated and feel more like an afterthought to health authorities. A related intention of the intervention was to provide residents with the benefit of knowing that the Metis Federation had their well-being in mind and was taking steps to ensure their protection from the pandemic.

Well basically that they were feeling that they're being paid attention to and that it would reduce the incidence of $\mathrm{H} 1 \mathrm{~N} 1$, because they're getting the hand washing and the messaging, you know the etiquette, sneeze, coughs, those kinds of things. And basically that was what we were after is just to make sure that they knew that they were being included and they were getting the correct preventive information (Manitoba Metis Federation, key informant interview, 7 July 2011).

Altogether, the educational and collegial goals of the visitation were envisioned to be a considerable investment of time for each visit, a process that was not to be rushed:

It would probably be at least 30 minutes of time .... Yes, 30 minutes to an hour because you never go in and just-that's not the way you do it, you go in and you have tea (Manitoba Metis Federation, key informant interview, 7 July 2011).

The MMF-HWD does not provide or deliver health services to Metis constituents, nor have the requisite human resources necessary to carry out home health visitations throughout the province. At the same time, while the health system has the ultimate responsibility for disseminating pandemic risk messaging, they did not have the knowledge needed for a targeted intervention to reach individual Metis households in remote areas. The MMF-MCLD was uniquely positioned with staff in all Regions due to their role as service providers, albeit not generally health-related. With MMF-MCLD's outreach functions and close work with Metis citizens, it was presumed that MMF-MCLD staff were much more familiar with the targeted areas. They were most suitably placed to navigate the practicalities in reaching Metis in remote areas, and thus agreed to partner on the intervention. The MMF-HWD would only train the MMF-MCLD staff on the healthrelated content of the visitations.

Ultimately the health system should have been providing this information but they, frankly didn't know how. They do not know how to reach Metis citizens in these isolated areas .... And so when we approached [the MCLD Director] and said "This is what the President wants and it makes more sense that your staff go in 
because they're going into these communities all the time," she just thought that was great and that we would train her staff. And she wouldn't have to worry about the content; she would just worry about the administrative [aspects of] getting them out there and stuff like that (Manitoba Metis Federation, key informant interview, 7 July 2011).

\section{Training}

Training the MMF-MCLD messengers occurred in mid-December 2009 and regional staff were given basic information on $\mathrm{H} 1 \mathrm{~N} 1$ and instructions for the intervention by MMFHWD staff. MMF-MCLD staff were told about the ANA flu kits already distributed and the joint MMF-Manitoba Health informational mail-out that residents may have already received. Instructions stressed that MMF-MCLD messengers were not to give health advice due to potential issues of legal liability, and any questions posed to them by residents were to be re-directed to the resident's health provider or to the province's 24-hour telephone health information service staffed by registered nurses, known as Health-Links/Info-Santé. And while staff could direct residents to a flu kit, they could not involve themselves in any of the contents as the kits were the responsibility of the province that distributed them.

Being very careful that when we train these staff that they do not provide health advice because they're not healthcare providers .... It's like you can't give a person advice of, you know, "my baby's coughing and they look like they have a fever; do you think they have a fever?" .... Health advice would be giving them advice on anything other than what's in [the mail-out] .... And it's pretty basic, what is the flu, how does it spread, what are the symptoms, how do I stay healthy, hand washing (Manitoba Metis Federation, key informant interview, 7 July 2011).

Prohibitions also applied to reading any instructions or labels on items such as medicine bottles or thermometers, whether residents received in the kit or otherwise, as this was also considered to be giving health advice.

So if there's Tylenol for Infants; if asked, "Well how many drops do I give my baby?" you can't tell them that. You say, "If you don't know you have to call Health-Links or your health provider" .... That's providing medical support and only a qualified health provider can do that .... That's a nursing duty, or a Nurse's Aide or something; someone who has been assessed as qualified to provide that. And the reason for that is because of the legal liability issues that would occur if something went wrong. So we really had to try to be really clear. I mean you never know for sure if people follow the instructions and don't do that, but you really don't want them giving any kind of medical advice because they are not qualified and the best place is to phone Health-Links (Manitoba Metis Federation, key informant interview, 7 July 2011).

The following instructions summed-up the MMF-MCLD messenger's role (quoted from training presentation): 


\section{- It is not your role to give health advice}

- Your are confirming receipt of a flu kit and/or health information mail out

- If they don't have a flu kit refer households to [ANA] office

- If they didn't receive mail out give them information during your visit

- For specific health information refer people to the nearest health provider or health links [for people who may have questions about H1N1 or other health issues beyond received kits and/or mail out] (Manitoba Metis Federation, received during key informant interview, July 7 2011, bolded in original)

Researcher field notes captured discussions between researchers and MMF-MCLD staff who carried out the messaging campaign and indicate that further instructions were given to messengers in their respective Regions. Staff were instructed never to be alone and to avoid places that looked dangerous. They were to wait outside or in the doorway at residences and to complete a brief survey with the residents-the survey asked residents about their cultural identification, number of occupants in the household, if the household had a flu kit, and whether anyone had been vaccinated for H1N1.

\section{Metis Perceptions of Home Visitations}

During the focus groups, researchers asked residents if they recalled any visits to their houses from MMF staff during the pandemic. Participants aged 18-34 in one community indicated that they had little recollection of the intervention, and if they did recall that someone visited, they simply remembered that someone had visited but little else:

"Yeah." [When asked if she could remember MMF visiting]

"I don't think I was home."

"I don't think I answered the door."

"I don't think they got inside my door; I've got like four little dogs coming running at the door, so."

"What did they come to [our community] for last year?"

In the same community, residents aged 35-54 who recalled a visit from MMF staff indicated that the visitors briefly asked a few questions and inquired about the flu kits sent to community by ANA.

"Somebody did a little survey or something."

“Two women came to my house ... asked, asked about it." 
“They asked us if we got our kits."

"And that you, if you did not [have a kit], I think you could go pick some up in town or wherever they were, or notify the nurse, the nursing station there and they will give it [to] you or something like that, I don't know."

Two participants did say "yes" when asked if they recalled a visit from the MMF; however three others replied "no" and another replied that they were not home at the time. One resident refused to let the staff in.

“They looked like Jehovah Witnesses, I didn't let them in."

None of the residents over 55 years of age in the same community recalled any visits from the MMF.

"Never heard from them."

In both focus groups conducted in the other community, none of the participants recalled a visit from the MMF.

"No, I don’t think so."

\section{Discussion}

The province's efforts to protect Metis in Manitoba during the pandemic incorporated strategies recommended by recent literature on pandemic risk communications, particularly in terms of partnerships between health systems and at-risk communities, adopting an approach more in line with social justice imperatives and avoiding a "onesize-fits-all" messaging approach (Gray et al. 2012; Uscher-Pines et al. 2007; Hutchins et al. 2009; Lee, Rogers, and Braunack-Mayer 2008). The MMF-HWD already had an established relationship with Manitoba Health and provincial Regional Health Authorities as part of their Regional Knowledge Networks, and these connections quite likely helped to facilitate a collaborative response to the pandemic. The provincial health systems quickly engaged with the Manitoba Metis' representative organization, giving the Metis the opportunity to share valuable Metis-specific health knowledge, to pinpoint where the greatest challenges lie, and to work together on generating solutions. The collaboration between the MMF and the province signals a positive step towards offsetting the social exclusion that has long characterized the experience of the Metis in Canada. The Metis community's active involvement in organizing a more targeted, culturally relevant response to the pandemic was a constructive exercise in giving the Metis a "voice" during a public health threat. At the same time, a Metis-specific pandemic response implies an acknowledgement of some the unique challenges that many Metis in Manitoba face. Indeed, the Metis' past dispossessions of land, geographical dispersals, experiences with institutional and interpersonal racism, and other colonially related outcomes, are clearly reflected in their disparities in health status-disparities that are made much more understandable when connected to their social determinants (Reading and Wien 2009). Inequities in health paralleled those in political, economic, and social realms. Set in the context of the H1N1 pandemic, the consequences 
of such historically rooted disparities was ultimately an elevated risk of infection and severity. The potential for acute pandemic vulnerability culminated in a number of targeted interventions carried out during the second wave. Interestingly, the interventions evolved to have a target-within-a-target approach: a unique approach that recognized a generalized state of health inequity as well as geographic differentials in Metis population health. As a result, not only was the entire MMF membership sent risk communication messaging via a mail-out, but even the potentially most vulnerable segments within the Metis population were further targeted to receive a home health visitation and access to flu kits.

Despite these positive efforts and developments, the focus group participants' responses suggest that the door-to-door intervention may not have been as effective as intended. Most participants did not recall a visit from the MMF, and those who did reported that the visit was a very brief encounter and consisted of a "short survey." Of course, it should be noted that it is quite likely that Metis who did receive a visit from MMF did not participate in the focus groups, and likewise that Metis who were not present found the intervention valuable and helpful. However, when participant responses are examined together with the training and practicalities involved in the campaign, reasons for a divergence between intention and outcome become increasingly apparent. Indeed, a number of factors cumulatively reduced what the intervention could achieve.

A key factor for any pandemic communications campaign is timing (Gray et al. 2012). In this case, the visitations took place after the vaccine had been made available and during the decline of the second wave. The pandemic's period of peak activity had passed, rates of infection were falling, pandemic responses were already de-escalating, and in Manitoba the hospitalization rates were lower in the second wave than in the first (Public Health Agency of Canada 2010). With the pandemic threat declining from the public's view, it is possible that a visit designed to emphasize prevention would have gained less traction, or been less memorable, than earlier in the pandemic. In this case, the intervention may have been too late to be properly effective.

Equally important for effective risk communication is how messaging is delivered. Selecting MMF-MCLD staff to act as the messengers for this intervention would have certainly satisfied key criteria. On one hand, they were presumed to have had a pre-existing familiarly with the targeted regions and, by extension, the people who may live there. On the other hand, messages can resonate more strongly with targeted audiences if they are delivered by local, or in-community, representatives (Rudge and Massey 2010; Massey et al. 2009; Massey et al. 2011). Of course, this was only a single-visit intervention, and having messengers acquainted with the landscape and their community could help to offset the absence of long-term, relationship-building visitations recommended in literature (Kearney, York, and Deatrick 2000). As it turned out, staff familiarity with the targeted areas may have been overestimated-depending on the levels of prior activity between the MCLD, the communities, and individual Metis families. Without a perception of incommunity familiarity, residents may not have even realized that a health messenger was a representative of the MMF, but perhaps an official or a person merely taking a survey. Moreover, visitations have been linked to better outcomes when they are carried out by 
health system staff, generally nurses, and not members of the lay community (Kearney, York, and Deatrick 2000; Government of Manitoba 2010a). Nurses are legally able to give health advice, answer questions, and address individual concerns. MCLD staff were not trained to give health advice and they were told they could not answer questions or respond to specific requests, such as reading the appropriate government-approved worded instructions of a thermometer or medicine bottle for someone who might have a low level of literacy.

Although the initial design of the intervention consisted of the messengers spending a considerable amount of time at each residence, their instructions significantly limited the scope of the messengers' activities. Visitors were instructed to only inquire whether residents had received the flu kit and the MMF mail-out, and to direct any inquiries to Health-Links/Info-Santé. These instructions were later converted by MMF-MCLD into a brief survey that they administered to each household. The reduction of the MMF-MCLD staff's H1N1 messaging activities cumulatively diminished any educative or relationshipbuilding role for the messengers, and further limited the time spent at houses to only a minute or two. Given their brief nature it is possible that some residents may not have even remembered a visit, much less any educational content it was intended to impart.

In a purely practical sense, the staff who carried out the campaign would likely have experienced a variety of challenges, particularly since the intervention took place in January and February in northern Manitoba. Staff would probably have encountered travel conditions that rendered roads impassable due to snow or inclement weather. Furthermore, visiting remote communities would have involved demanding timeframes and occasionally have required messengers to hastily ensure that they reach as many households of a community as they could to avoid returning for only a few houses or having to spend the night (particularly where accommodation is not easily available in some remote and isolated communities). Finally, some residents may have been simply impossible to reach.

\section{Conclusion}

Although participant feedback indicates that the intervention may have fallen short of its intended goals, the exercise does offer a number of important lessons for future pandemic communication planning. Certainly, these targeted interventions should be recognized as a significant improvement over traditional "one-size-fits-all" communication campaigns. In particular, the target-within-a-target approach highlights the fact that targeted interventions must be customized to reflect the unique character of the targeted population and be sensitive to a population's internal diversity.

Public health experts commonly claim that the next pandemic is not a matter of "if," but "when" (Pascoe 2006; U.S. Department of Health \& Human Services n.d.). Additionally, not only are pandemics inherently filled with uncertainty, but events can move at such a pace that policy-makers can often only play catch-up as circumstances unfold. This is precisely why inter-pandemic planning is critical to effective pandemic communication strategies. In this case, the established relationship between the MMF and the provincial health system prior to the pandemic meant that some of the important groundwork for 
effective partnerships had already taken place. Having mechanisms in place for respectful community partnerships is important, but more strategizing can be done to tackle the significant challenges that are involved in protecting communities that may be more at-risk-for example, getting messaging out to remote and isolated communities where Metis live. As timing is crucial, having at least rudimentary plans on hand and ready to be expedited is an immediate take-away lesson from this evaluation, and such plans can also "build-in" for inevitable logistical obstacles that can cumulatively amount to significant delays. Actions can be taken now to plan innovative ways to get culturally relevant information into a targeted audience's hands in a timely fashion and when it could have the greatest preventative effect. It is in the inter-pandemic period where real strides can be made to ensure that past efforts are reviewed, key issues are addressed, obstacles identified, and solutions generated.

The MCLD staff who carried out the intervention were not trained healthcare workers, and therefore were constrained in their abilities to response to residents' inquiries or to go "off-script" from their surveys. This challenge reflects a difficulty in finding the delicate balance between the goal of giving health advice and having in-community representatives deliver health messaging so that it resonates better with the audience (Massey et al. 2011; Massey et al. 2009; Rudge and Massey 2010). In the current study, the inability to give health advice or more in-depth interaction may have not only reduced the scope and length of the visits, but also reduced intended message efficacy and collegiality. New messaging strategies are needed that successfully incorporate both the localized in-community context and health expertise components. One possible solution could be to extend the systemscommunity partnership to the local level. In this case, many of the remote and isolated ANA communities have a community health centre staffed generally by a community health worker who functions as the local "go-to" person trained to give health advice and care. Localized partnerships, involving the community health workers and Regional MMF staff-for example, in a community health meeting setting during a pandemiccould ensure that residents are able to access qualified health advice that is also mediated in a localized and culturally appropriate way. At the same time, continued evaluations of targeted pandemic risk communication interventions are necessary to provide further insights into potential challenges, as well as innovative mechanisms for dissemination.

Protecting those who could be most vulnerable to a pandemic should be a top priority for health systems (Uscher-Pines et al. 2007). The context of Canada's colonial past and present, and the related political, economic, social, and health disparities that are its result, have made Metis a particularly at-risk population, a recognition of the fact that pandemics affect populations unequally and in ways that reflect existing inequities (Lee, Rogers, and Braunack-Mayer 2008). While the intervention in question may not have been as successful as hoped, it should not discourage consideration of similar endeavors for future pandemic scenarios. Instead, it should prompt further refinement of targeted strategies. This is not simply a matter of achieving systems efficiency as it is also a matter of social justice. From a much broader yet equally critical perspective, action also needs to be directed at fundamental social structures that determine and perpetuate disparities in health status and related vulnerabilities in the first place. 


\section{Acknowledgements}

The authors extend their sincere gratitude to all of the study participants who shared their time, experiences, and thoughts with us. We also thank the Manitoba Metis Federation for their valuable collaboration in the research, as well as Elizabeth Cooper, University of Manitoba, who was the research associate who helped facilitate data collection and initial analysis. We gratefully acknowledge the thoughtful comments of two external reviewers whose input greatly strengthened the manuscript. This research project was supported by a grant from the Canadian Institutes of Health Research (CIHR), Institutes of Aboriginal Peoples' Health: CIHR Operating Grant, 2010-2013 (MOP 102623) and CIHR and Manitoba Health Research Council Regional Partnerships Program, 2009-2013 (MOP 100426). An equipment and infrastructure grant from the Canadian Federation for Innovation and the Manitoba Research and Innovation Fund also supported this research (202990). 


\section{Bibliography}

Adelson, N. 2005. “The Embodiment of Inequality: Health Disparities in Aboriginal Canada." Canadian Journal of Public Health 96 (Suppl 2): S45-61.

Andersen, C. 2008. "From Nation to Population: The Racialisation of 'Métis' in the Canadian Census." Nations \& Nationalism 14 (2): 347-68.

Baker, A. C., and A. R. Giles. 2012. "Cultural Safety: A Framework for Interactions between Aboriginal Patients and Canadian Family Medicine Practitioners." Journal of Aboriginal Health 9 (1): 15-22.

Bartlett, J. G., S. Carter, J. Sanguins, and B. Garner. 2012. "The Use of a Holistic Wellnes Framework and Knowledge Networks in Métis Health Planning." In Citizen Engagement in Health Casebook, 51-56. Ottawa: Canadian Institutes of Health Research. Accessed 19 March 2014. http://www.cihr-irsc.gc.ca/e/47596.html.

Blumenshine, P., A. Reingold, S. Egerter, R. Mockenhaupt, P. Braveman, and J. Marks. 2008. "Pandemic Influenza Planning in the United States from a Health Disparities Perspective." Emerging Infectious Diseases 14 (5): 709-15. http://dx.doi.org/10.3201/ eid1405.071301.

Boggild, A., L. Yuan, D. Low, and A. McGeer. 2011. “The Impact of Influenza on Canadian First Nations." Canadian Journal of Public Health 102 (5): 345-48.

Browne, A. J. 2007. "Clinical Encounters between Nurses and First Nations Women in a Western Canadian Hospital." Social Science and Medicine 64 (10): 2165-176. http:// dx.doi.org/10.1016/j.socscimed.2007.02.006.

Browne, A. J., V. Smye, P. Rodney, S. Tang, B. Mussell, and J. O’Neil. 2010. “Access to Primary Care from the Perspective of Aboriginal Patients at an Urban Emergency Department." Qualitative Health Research 21 (3): 333-45. http://dx.doi. org/10.1177/1049732310385824.

Byrd, M. E. 1995. “A Concept Analysis of Home Visiting.” Public Health Nursing 12 (2): 83-89. http://dx.doi.org/10.1111/j.1525-1446.1995.tb00129.x.

Cook, C. 2003. "Jurisdiction and First Nations Health and Health Care." Masters thesis, University of Manitoba.

Crabtree, B., and W. L. Miller, eds. 1999. Doing Qualitative Research. 2nd ed. Thousand Oaks: Sage Publications.

Dickason, O. P. 1992. Canada's First Nations: A History of Founding Peoples from Earliest Times. Toronto, ON: McClelland and Stewart.

Driedger, S. M., C. G. Jardine, C. Furgal, and J. G. Bartlett. 2009-2010. Risk and Trust in Government Action: Lessons from Case Studies in Canada. Winnipeg: Canadian Institutes of Health Research-Manitoba Health Research Council Regional Partnerships Program.

- - - 2010-2013. Risk and trust in government action: Lessons from case studies in Canada. Canada: Canadian Institutes of Health Research. 
Federal Court of Canada. 2013. Harry Daniels, Gabriel Daniels, Leah Gardner, Terry Joudrey and The Congress of Aboriginal Peoples and Her Majesty The Queen, as represented by the Minister of Indian Affairs and Northern Development and The Attorney General of Canada: Reasons for Judgement. Docket no. T-2172-99. Ottawa: Federal Court of Canada. http://decisions.fct-cf.gc.ca/site/fc-cf/decisions/en/61753/1/document.do.

Freiman, A. J., J. P. Montgomery, J. J. Green, D. L. Thomas, A. M. Kleiner, and M. L. Boulton. 2011. "Did H1N1 Influenza Prevention Messages Reach The Vulnerable Population along the Mississippi Gulf Coast?" Journal of Public Health Management Practice 17 (1): 52-58. http://dx.doi.org/10.1097/PHH.0b013e3181fb8002.

Furgal, C. M., T. D. Garvin, and C. G. Jardine. 2010. “Trends in the Study of Aboriginal Health Risks in Canada." International Journal of Circumpolar Health 69 (4): 322-32.

Gaudry, A. 2013. “The Métis-ization of Canada: The Process of Claiming Louis Riel, Métissage, and the Métis People as Canada's Mythical Origin." Aboriginal Policy Studies 2 (2): 64-87. http://dx.doi.org/10.5663/aps.v2i2.17889.

Gilchrist, V. 1992. “Key Informant Interviews.” In Doing Qualitative Research, ed. B. F. Crabtree and W. L. Miller, 70-89. Newbury Park: Sage Publications.

Giles, A. R., H. Castleden, and A. C. Baker. 2010. "We listen to our Elders, you live longer that way": Examining aquatic risk communication and water safety practices in Canada's North." Health and Place 16:1-9.

Glik, D. C. 2007. "Risk Communication for Public Health Emergencies." Annual Review of Public Health 28: 33-54. http://dx.doi.org/10.1146/annurev. publhealth.28.021406.144123.

Government of Canada. 1982. Constitution Acts, 1867 to 1982: Section 35. Accessed 17 December 2013. http://lois.justice.gc.ca/eng/Const/page-16.html\#h-52.

-_- 2009. H1N1 Flu in Manitoba: Pandemic Flu Plan-Fall/Winter 2009. Winnipeg: Government of Manitoba. https://www.gov.mb.ca/asset_library/flu/executive_ summary.pdf.

- - . 2010a. Families First Program Evaluation: Evaluating the Effectiveness of the Families First Home Visiting Program in Improving the Well-Being of At-Risk Families with Preschool Children. Winnipeg: Government of Manitoba. http://www.gov.mb.ca/ healthychild/familiesfirst/ff_eval2010.pdf.

- - . 2010b. H1N1 Flu in Manitoba: Manitoba's Response Lessons Learned. Winnipeg: Government of Manitoba. Accessed 17 March 2014. http://www.gov.mb.ca/health/ documents/h1n1.pdf.

- - - n.d. a. Aboriginal and Northern Profile. Winnipeg: Aboriginal and Northern Affairs. Accessed 17 December 2013. http://www.gov.mb.ca/health/documents/h1n1.pdf.

- - - n.d. b. Community Profiles.. Winnipeg: Aboriginal and Northern Affairs. Accessed 17 December 2013. http://www.gov.mb.ca/ana/community_profiles/index.html.

Gray, L., C. MacDonald, B. Mackie, D. Paton, D. Johnston, and M. G. Baker. 2012. "Community responses to communication campaigns for Influenza A (H1N1): A focus group study." BMC Public Health 12: 205. http://dx.doi.org/10.1186/14712458-12-205. 
Haworth-Brockman, M. J. , K. Bent, and J. Havelock. 2009. "Health research, Entitlements and Health Services for First Nations and Métis Women in Manitoba and Saskatchewan." Journal of Aboriginal Health 4 (2): 17-23.

Hewagama, S., S. P. Walker, R.L. Stuart, C. Gordon, P. D. R. Johnson, N. D. Friedman, M. O'Reilly, A. C. Cheng, and M. L. Giles. 2010. “2009 H1N1 Influenza A and Pregnancy Outcomes in Victoria, Australia." Clinical Infectious Diseases 50: 686-90. http://dx.doi.org/10.1086/650460.

Hutchins, S. S., K. Fiscella, R. S. Levine, D. C. Ompad, and M. McDonald. 2009. "Protection of Racial/Ethnic Minority Populations during an Influenza Pandemic." American Journal of Public Health 99 (S2): S261-S270. http://dx.doi.org/10.2105/ AJPH.2009.161505.

Israel, B., A. Schulz, E. Parker, and A. Becker. 1998. "Review of Community-Based Research: Assessing Partnership Approaches to Improve Public Health.” Annual Review of Public Health 19: 173-202. http://dx.doi.org/10.1146/annurev.publhealth.19.1.173.

Jardine, C. G. 2008. "Evaluation of Risk Communication Efforts." In Encyclopedia of Quantitative Risk Analysis and Assessment, ed. E. Melnick and B. Everitt. Chichester: Wiley Press.

Jehn, M., Y. Kim, B. Bradley, and T. Lant. 2011. "Community Knowledge, Risk Perception, and Preparedness for the 2009 Influenza A/H1N1 Pandemic." Journal of Public Health Management Practice 17 (5): 431-38. http://dx.doi.org/10.1097/ PHH.0b013e3182113921.

Kearney, M. H., R. York, and J. A. Deatrick. 2000. "Effects of Home Visits to Vulnerable Young Families." Journal of Nursing Scholarship 32 (4): 369-76. http://dx.doi. org/10.1111/j.1547-5069.2000.00369.x.

Krueger, R. A. 1988. Focus Groups: A Practical Guide for Applied Research. Newbury Park: Sage Publications.

Kumar, M. B., S. Wesche, and C. McGuire. 2012. “Trends in Métis-related health research (1980-2009): Identification of Research Gaps.” Canadian Journal of Public Health 103 (1): 23-28.

La Ruche, G., A. Tarantola, P. Barboza, L. Vaillant, J. Gueguen, and M. Gastellu-Etchegorry, for the epidemic intelligence team at InVS. 2009. “The 2009 pandemic H1N1 influenza and Indigenous Populations of the Americas and the Pacific." Eurosurveillance 14 (42):pii=19366.

Larson, A., M. Gillies, P.J. Howard, J. Coffin. 2007. “It's Enough to Make You Sick: The Impact of Racism on the Health of Aboriginal Australians." Australian and New Zealand Journal of Public Health 31: 322-29. http://dx.doi.org/10.1111/j.17536405.2007.00079.x.

Lee, C., W. A. Rogers, and A. Braunack-Mayer. 2008. "Social Justice and Pandemic Influenza Planning: The Role of Communication Strategies." Public Health Ethics 1 (3): 22334. http://dx.doi.org/10.1093/phe/phn031.

Liamputtong, P. 2011. Focus Group Methodology: Principles and Practice. Los Angeles: Sage Publications. 
Louie, J. K., M. Acosta, K. Winter, C. Jean, S. Gavali, R. Schechter, and D. Vugia, et al. 2009. "Factors Associated with Death or Hospitalization Due to Pandemic 2009 Influenza A (H1N1) Infection in California." Journal of the American Medical Association 302 (17): 1896-902. http://dx.doi.org/10.1001/jama.2009.1583

Lux, M. 2001. Medicine That Walks: Disease, Medicine and Canadian Plains Native People, 1880-1940. Toronto: University of Toronto Press.

- - - 2010. "Care for the 'Racially Careless': Indian Hospitals in the Canadian West, 1920-1950s.” The Canadian Historical Review 91 (3): 407-34.

Maier, R., E. Cooper, and S. M. Driedger. 2012. Report on the H1N1 Pandemic Response of the Manitoba Metis Federation: An Evaluation of Health Risk Messaging Interventions. Winnipeg: University of Manitoba.

Manitoba Metis Federation. 2013a Who are the Metis? Accessed 17 December 2013. http:// www.mmf.mb.ca/who_are_the_metis.php

_-_. 2013b. Objectives. Accessed 17 December 2013. http://www.mmf.mb.ca/objectives. php

-_- 2013c. Metis Community Liaison Department. Accessed 17 December 2013. http:// www.mmf.mb.ca/departments_portfolios_and_affiliates_details.php?id=7

Martens, P. J., J. G. Bartlett, E. M. J. Burland, H. J. Prior, C. A. Burchill, S. Huq, L. Rompf, and J. Sanguins, et al. 2010. Profile of Metis Health Status and Healthcare Utilization in Manitoba: A Population-Based Study. Winnipeg: Manitoba Centre for Health Policy.

Massey, P. D., A. Miller, S. Saggers, D.N. Durrheim, R. Speare, K. Taylor, and G. Pearce, et al. 2011. "Australian Aboriginal and Torres Strait Islander Communities and the Development of Pandemic Influenza Containment Strategies: Community Voices and Community Control." Health Policy 103: 184-90. http://dx.doi.org/10.1016/j. healthpol.2011.07.004

Massey, P. D., G. Pearce, K. A. Taylor, L. Orcher, S. Saggers, and D. N. Durrheim. 2009. "Reducing the Risk of Pandemic Influenza in Aboriginal Communities." Rural and Remote Health 9: 1290.

McMillan, A. D. 1995. Native Peoples and Cultures of Canada. 2nd ed. Vancouver: Douglas \& Mcintyre.

Morgan, D, and R Krueger. 1993. "When to Use Focus Groups and Why." In Successful Focus Groups: Advancing the State of the Art, edited by D. Morgan, 3-19. Newbury Park, CA: Sage.

Pascoe, N. 2006. "A Pandemic Flu: Not If, but When-SARS Was the Wake-Up Call We Slept Through." Texas Nursing 80 (1): 6-10.

Patton, M. Q. 2002. Qualitative Research \& Evaluation Methods. 3rd ed. Thousand Oaks, CA: Sage Publications.

Pebody, R .G., E. McLean, H. Zhao, P. Cleary, S. Bracebridge, K. Foster, and A. Charlett, et al. 2010. "Pandemic Influenza A (H1N1) 2009 and mortality in the United Kingdom: Risk factors for death, April 2009 to March 2010." Eurosurveillance 15 (20):pii=19751. 
Pollock, S.L., M. Sagan, L. Oakley, J. Fontaine, and L. Poffenroth. 2012. "Investigation of a Pandemic H1N1 Influenza Outbreak in a Remote First Nations Community in Northern Manitoba, 2009." Canadian Journal of Public Health 103 (2): 90-93.

Public Health Agency of Canada. 2010. PHAC Lessons Learned Review: Public Health Agency of Canada Response to the 2009 H1N1 Pandemic. Ottawa: Public Health Agency of Canada.

Quinn, S. C. 2008. "Crisis and Emergency Risk Communication in a Pandemic: A Model for Building Capacity and Resilience of Minority Communities." Health Promotion Practice 9 (4): 18S-25S.

Reading, C. L., and F. Wien. 2009. Health Inequalities and Social Determinants of Aboriginal Peoples' Health. Prince George, BC: National Collaborating Centre for Aboriginal Health.

Rudge, S., and P. D. Massey. 2010. "Responding to Pandemic (H1N1) 2009 Influenza in Aboriginal Communities in NSW through Collaboration between NSW Health and the Aboriginal Community-controlled Health Sector." NSW Public Health Bulletin 21 (1-2): 26-29. http://dx.doi.org/10.1071/NB09040

Sanguins, J., J. G. Bartlett, S. Carter, and B. Garner. 2012. 'Knowledge from the People, for the People': Using Knowledge Networks to Influence Health Programs and Services for Metis in Manitoba. Paper presented at University of Manitoba Workshop Celebrating First Nations and Métis Research Partnerships, Winnipeg, MB, March 2012. http://chrr.info/images/stories/Knowledge_from_the_people_for_the_ people_Celebrating_2012.pdf

Spence, N., and J. P. White. 2010. "Scientific Certainty in a Time of Uncertainty: Predicting Vulnerability of Canada's First Nations to Pandemic H1N1/09." The International Indigenous Policy Journal 1 (1). http://ir.lib.uwo.ca/iipj/vol2/iss1/

Statistics Canada. 2008. Aboriginal Peoples in Canada in 2006: Inuit, Metis and First Nations, 2006 Census. Catalogue no. 97-558-XIE. Ottawa: Ministry of Industry. http://www12.statcan.ca/census-recensement/2006/as-sa/97-558/pdf/97-558XIE2006001.pdf

Tang, S. Y., and A. J. Browne. 2008. “'Race' matters: racialization and egalitarian discourses involving Aboriginal people in the Canadian health care context." Ethnicity and Health 13 (2): 109-27.

Thobani, S. 2007. Exalted Subjects: Studies in the Making of Race and Nation in Canada. Toronto: University of Toronto Press.

U.S. Department of Health \& Human Services. n.d. The Next Flu Pandemic: What to Expect. Accessed 5 July 2013. http://www.flu.gov/planning-preparedness/community/ nextflupandemic.html

U.S. National Research Council. 1989. Improving Risk Communication. Washington, DC: National Academy Press. 
Uscher-Pines, L., P. S. Duggan, J. P. Garoon, R. A. Karron, and R. R. Faden. 2007. "Planning for an influenza Pandemic: Social Justice and Disadvantaged Groups." Hastings Center Report 37 (4): 32-39. http://dx.doi.org/10.1353/hcr.2007.0064.

Vaughan, E., and T. Tinker. 2009. "Effective Health Risk Communication about Pandemic Influenza for Vulnerable Populations." American Journal of Public Health 99 (S2): S324-32. http://dx.doi.org/10.2105/AJPH.2009.162537.

World Health Organization. 2009. World Now at the Start of 2009 Influenza Pandemic. Accessed 5 July 2013. http://www.who.int/mediacentre/news/statements/2009/ h1n1_pandemic_phase6_20090611/en/.

- - - 2010. H1N1 in Post-Pandemic Period. World Health Organization. Accessed 5 July 2013. http://who.int/mediacentre/news/statements/2010/h1n1_vpc_20100810/en/. 